\title{
Conformational analyses of an alanine oligomer during chain propagation using quantum chemical calculations
}

\begin{abstract}
Minoru Kobayashi ${ }^{1}$, Jae Ho Sim $^{2}$ and Hisaya Sato $^{3}$
Conformational convergent calculations of alanine oligomer models (from 2- to 7-mer, $x=2-7$ ) were performed using QCC starting from the 2 -mer $(4 \times 164$ types). The energies and dihedral angle distributions $(\varphi / \psi)$ of the conformers were examined, and the results were compared with the experimental and calculated data previously reported by other authors. The two end group types (that is, 'amide type' and 'methyl type') and the left- and right-handed rotational directions were determined. The number of conformers decreased as $\mathrm{x}$ increased, and those of the 'methyl type' were larger than those of the 'amide type'. The $\varphi / \psi$ of the 4- to 7-mers converged to three types (that is, $\alpha$-helix $(g+/ g+$ or $g-/ g-)$, PPII-like $(g+/ g-$ or $g-/ g+)$ and $\beta$-extended $(t+/ t-$ or $t-/ t+)$ in decreasing energy order). The stabilities of the $\alpha$-helix increased as $x$ increased because of the intramolecular hydrogen bonds between amino acids located two or three units apart. The PPII-like type was different from the reported PPII $(\mathrm{g}-/ \mathrm{t}+)$ type and considered to be a 2.27 ribbon $(\mathrm{g}-/ \mathrm{g}+)$. No energy differences were observed between the left- and righthanded 'amide type'. However, energy differences were observed for the 'methyl type'. The unique energies and conformations of the 'methyl type' are mainly because of intramolecular hydrogen bonding.
\end{abstract}

Polymer Journal (2015) 47, 369-378; doi:10.1038/pj.2015.8; published online 4 March 2015

\section{INTRODUCTION}

A thorough understanding of the conformations of oligopeptides is important because these conformations often reflect the conformational formation during chain propagation. Many experimental and theoretical studies of the conformations of oligopeptides have been reported. For example, alanine oligomers have been studied using Raman (dimer) by Parchansky et al., ${ }^{1}$ NMR (trimer) by R. SchweitzerStenner, ${ }^{2}$ NMR (heptamer) by Shi et al., ${ }^{3}$ molecular dynamics (MD) and IR by Woutersen et al., ${ }^{4,5} \mathrm{MD}$ and NMR by Graf et al., ${ }^{6}$ QCC by Mirkin and $\mathrm{Krimm}^{7}$ and MD by Kentsis et al. ${ }^{8}$ However, analytical studies of the conformation of alanine oligomers during chain propagation are limited.

We previously reported the conformational analyses of methyl methacrylate, ethylene oxide and ethylene imine oligomers using a quantum chemical calculation (QCC) method. The results calculated for the isotactic methyl methacrylate oligomer ${ }^{9}$ supported the results (10/1 helix) observed for the 3- and 7-mers. The results calculated for the hydrated or non-hydrated ethyleneoxide ${ }^{10}$ and polyethylene imine ${ }^{10-12}$ oligomers supported the observed results, and the result for polyethylene imine enabled us to gain insight into the transition during hydration (from helix to extended). In this study, the QCC method was applied to alanine oligomers. For a deeper understanding of the conformation changes during chain propagation of the peptide, conformational convergent calculations of alanine oligomers from 2- to 7-mer (in the order starting from 2-mer) were performed, and the results were compared with the experimental data and the previously calculated values. For all of the models, the effects of the end group type and the left- and right-handed rotational directions of the main chain were examined. For the converged conformers, the energies and dihedral angle distributions of the main chain $\left[\left(\varphi_{n} / \psi_{n}\right)_{x}\right.$ in $\mathrm{CN}-\mathrm{C}^{\alpha} \mathrm{C} / \mathrm{NC}^{\alpha}-\mathrm{CN}$ ] are discussed.

\section{QUANTUM CHEMICAL CALCULATIONS}

Designations of alanine oligomer models

For oligomer models of the alanine, an x-mer of a single chain ( $\mathrm{x}$ : monomer unit number, $\mathrm{x}=2-7$ ) was prepared. The models are shown in Table 1. The 'amide type' and the 'methyl type' of end groups were used. In the 'amide type', the acetyl $\left(-\mathrm{NH}-\mathrm{COCH}_{3}\right)$ and methyl amide $\left(\mathrm{CH}_{3} \mathrm{NH}-\mathrm{CO}-\right)$ groups were designated as the $\mathrm{N}$ - and $\mathrm{C}$-end, respectively. In the 'methyl type', the methyl $\left(-\mathrm{NH}-\mathrm{CH}_{3}\right)$ and methyl amide $\left(\mathrm{CH}_{3} \mathrm{NH}-\mathrm{CO}-\right)$ groups were designated as the $\mathrm{N}$ - and C-end, respectively.

For the designations of the conformational distributions of each model, the main chain, which has dihedral angle distributions of $\left[\left(\chi_{n} / \varphi_{n} / \psi_{n}\right)_{x}\right]$ is $[(\pi / \pi / \pi)]_{\mathrm{x}}$, was prepared first. The $\left(\chi_{n} / \varphi_{n} / \psi_{n}\right)_{x}$ is the combinations of dihedral angles $\left(\tau_{\mathrm{n}}\right)$ repeated for the unit consisting

\footnotetext{
${ }^{1}$ Graduate School of Bio-Applications and Systems Engineering, Tokyo University of Agriculture and Technology, Koganei, Tokyo, Japan; ${ }^{2}$ Department of Advanced Material and Chemical Engineering, Halla University, Wonju, Korea and ${ }^{3}$ Graduate School of Technical Management, Tokyo University of Agriculture and Technology, Koganei, Tokyo, Japan Correspondence: Dr M Kobayashi, Graduate School of Bio-Applications and Systems Engineering, Tokyo University of Agriculture and Technology, Naka-cho, Koganei, Tokyo 184-8588, Japan.

E-mail: mikoba3@gmail.com

Received 21 November 2014; revised 28 December 2014; accepted 16 January 2015; published online 4 March 2015
} 
Table 1 Alanine oligomer models $(x=2-7$ mer $)$

\begin{tabular}{lccc}
\hline No. & Types of end groups & Molecular formula & Designations for rotational directions $\left(\tau_{\alpha(n)} \text { designated for HN-C }{ }^{\alpha} C H_{3}\right)^{a}$ \\
\hline xA1 & amide & $\mathrm{CH}_{3} \mathrm{CO}-\left[\mathrm{NHCH}\left(\mathrm{CH}_{3}\right) \mathrm{CO}\right]_{x}-\mathrm{NHCH}_{3}$ & left-handed $\left(120^{\circ}\right)$ \\
xA2 & amide & $\mathrm{CH}_{3} \mathrm{CO}-\left[\mathrm{NHCH}\left(\mathrm{CH}_{3}\right) \mathrm{CO}\right]_{x}-\mathrm{NHCH}_{3}$ & right-handed $\left(-120^{\circ}\right)$ \\
xM1 & methyl & $\mathrm{CH}_{3}-\left[\mathrm{NHCH}\left(\mathrm{CH}_{3}\right) \mathrm{CO}\right]_{x}-\mathrm{NHCH}_{3}$ & left-handed $\left(120^{\circ}\right)$ \\
xM2 & methyl & $\mathrm{CH}_{3}-\left[\mathrm{NHCH}\left(\mathrm{CH}_{3}\right) \mathrm{CO}\right]_{x}-\mathrm{NHCH}_{3}$ & right-handed $\left(-120^{\circ}\right)$ \\
\hline
\end{tabular}

aThe $\tau_{\alpha(n)}$ values are the dihedral angles designated for $\mathrm{HN}-\mathrm{C}^{\alpha} \mathrm{CH}_{3}$ bonds in all trans conformation: $\left[\left(\chi_{n} / \varphi_{n} / \psi_{n}\right)_{x}\right]=[(\pi / \pi / \pi)]_{x}$.

Table 2 Energies $(\Delta E)$ and structures $\left(\varphi_{n} / \psi_{n}\right)_{x}$ of converged conformers for the 'amide type'

\begin{tabular}{|c|c|c|c|c|c|c|c|c|c|c|c|}
\hline No & Designated models & $\Delta E$ (kcal per m.u.) & $\varphi_{n}, A v\left({ }^{\circ}\right)$ & $\psi_{n}, A v\left({ }^{\circ}\right)$ & Type $\varphi_{n} / \psi_{n}$ & No. & Designated models & $\Delta E$ (kcal per m.u.) & $\varphi_{n}, A v\left({ }^{\circ}\right)$ & $\psi_{n}, A_{v}\left({ }^{\circ}\right)$ & Type $\varphi_{n} / \psi_{n}$ \\
\hline $2 \mathrm{~A} 1-1$ & & -0.28 & 85.6 & -70.6 & $g+/ g-$ & $2 \mathrm{~A} 2-1$ & & -0.28 & -85.6 & 70.6 & $g-/ g+$ \\
\hline $2 A 1-2$ & & 0.00 & 159.4 & -162.9 & $t+/ t-$ & $2 \mathrm{~A} 2-2$ & & 0.00 & -159.4 & 162.9 & $\mathrm{t}-/ \mathrm{t}+$ \\
\hline $2 A 1-3$ & & 0.54 & -31.3 & 1.9 & $g-/ g+$ & $2 A 2-3$ & & 0.53 & -86.7 & -3.9 & $g-/ g-$ \\
\hline 2A1-4 & & 0.54 & 86.8 & 1.9 & $g+/ g+$ & $2 A 2-4$ & & 1.10 & -97.2 & 38.8 & $g-/ g+$ \\
\hline $2 A 1-5$ & & 1.10 & 97.2 & -38.7 & $g+/ g-$ & $2 A 2-5$ & & 1.91 & 74.6 & -57.1 & $g+/ g-$ \\
\hline $2 A 1-6$ & & 1.92 & -74.6 & 57.1 & $\mathrm{~g}-/ \mathrm{g}+$ & $2 A 2-6$ & & 2.70 & 65.0 & 22.5 & $g+/ g+$ \\
\hline $2 A 1-7$ & & 2.70 & -65.0 & -22.5 & $g-/ g-$ & $2 A 2-7$ & & 3.70 & -26.2 & 24.1 & $g-/ g+$ \\
\hline $2 A 1-8$ & & 3.70 & 26.2 & -24.1 & $g+/ g-$ & $2 A 2-8$ & & 4.64 & -141.4 & -28.3 & $t-/ g-$ \\
\hline $2 A 1-9$ & & 4.65 & 141.4 & 28.3 & $\mathrm{t}+/ \mathrm{g}+$ & $2 A 2-9$ & & 6.28 & -164.5 & -56.2 & $\mathrm{t}-/ \mathrm{g}-$ \\
\hline 2A1-10 & & 5.78 & -62.0 & 131.8 & $g-/ t+$ & & & & & & \\
\hline 2A1-11 & & 6.28 & 164.5 & 56.2 & $\mathrm{t}+/ \mathrm{g}+$ & & & & & & \\
\hline 3A1-1 & $2 A 1-1,5$ & -0.31 & 85.5 & -69.8 & $g+/ g-$ & $3 A 2-1$ & $2 A 2-3,6$ & -0.31 & -85.5 & 69.8 & $g-/ g+$ \\
\hline $3 A 1-2$ & 2A1-2 & 0.00 & 159.5 & -163.3 & $\mathrm{t}+/ \mathrm{t}-$ & $3 A 2-2$ & 2A2-2 & -0.06 & -78.0 & -26.6 & $g-/ g-$ \\
\hline $3 A 1-3$ & $2 A 1-3,4,8,9$ & 0.06 & 78.0 & 8.9 & $g+/ g+$ & $3 A 2-3$ & $2 \mathrm{~A} 2-1$ & 0.00 & -159.5 & 163.3 & $t-/ t+$ \\
\hline $3 A 1-4$ & $2 \mathrm{~A} 1-6,7,10$ & 1.78 & -74.7 & 56.3 & $g-/ g+$ & $3 A 2-4$ & $2 A 2-4,5$ & 1.78 & 74.7 & -56.3 & $g+/ g-$ \\
\hline $3 A 1-5$ & 2A1-11 & 1.95 & 144.5 & -47.3 & $\mathrm{t}+/ \mathrm{g}-$ & $3 A 2-5$ & $2 \mathrm{~A} 2-7,8$ & 1.95 & -144.5 & 47.2 & $t-/ g+$ \\
\hline $4 A 1-1$ & $3 A 1-3,5$ & -0.61 & 74.0 & 11.6 & $g+/ g+$ & $4 \mathrm{~A} 2-1$ & $3 A 2-5$ & -0.61 & -74.0 & -11.6 & $g-/ g-$ \\
\hline $4 A 1-2$ & $3 A 1-1,4$ & -0.33 & 85.4 & -69.2 & $g+/ g-$ & $4 A 2-2$ & $3 A 2-1$ & -0.33 & -85.4 & 69.2 & $g-/ g+$ \\
\hline \multirow[t]{3}{*}{$4 A 1-3$} & $3 A 1-2$ & 0.00 & 159.5 & -163.6 & $\mathrm{t}+/ \mathrm{t}-$ & $4 \mathrm{~A} 2-3$ & $3 A 2-3$ & 0.00 & -159.5 & 163.6 & $t-/ t+$ \\
\hline & & & & & & $4 A 2-4$ & $3 A 2-2$ & 0.27 & -94.8 & -14.4 & $g-/ g-$ \\
\hline & & & & & & $4 A 2-5$ & $3 A 2-4$ & 1.69 & 74.7 & -55.7 & $g+/ g-$ \\
\hline $5 A 1-1$ & $4 \mathrm{~A}-1$ & -1.05 & 71.5 & 13.6 & $g+/ g+$ & $5 A 2-1$ & $4 A 2-1,4$ & -1.05 & -71.5 & -13.6 & $g-/ g-$ \\
\hline $5 A 1-2$ & $4 \mathrm{~A}-2$ & -0.36 & 85.3 & -68.8 & $g+/ g-$ & $5 A 2-2$ & 4A2-2 & -0.36 & -85.3 & 68.8 & $g-/ g+$ \\
\hline \multirow[t]{2}{*}{$5 A 1-3$} & $4 A-3$ & 0.00 & 159.6 & -163.8 & $t+/ t-$ & $5 A 2-3$ & $4 \mathrm{~A} 2-3$ & 0.00 & -159.6 & 163.8 & $t-/ t+$ \\
\hline & & & & & & $5 A 2-4$ & $4 A 2-5$ & 1.61 & 74.6 & -55.3 & $g+/ g-$ \\
\hline $6 A 1-1$ & $5 \mathrm{~A} 1-1$ & -1.40 & 69.7 & 15.0 & $g+/ g+$ & $6 \mathrm{~A} 2-1$ & $5 A 2-1$ & -1.4 & -69.7 & -15.0 & $g-/ g-$ \\
\hline $6 A 1-2$ & $5 A 1-2$ & -0.40 & 85.2 & -68.5 & $g+/ g-$ & $6 \mathrm{~A} 2-2$ & $5 A 2-2$ & -0.39 & -85.2 & 68.5 & $g-/ g+$ \\
\hline \multirow[t]{2}{*}{$6 A 1-3$} & $5 A 1-3$ & 0.00 & 159.6 & -163.9 & $\mathrm{t}+\mathrm{t}-$ & $6 \mathrm{~A} 2-3$ & $5 A 2-3$ & 0.00 & -159.6 & 163.9 & $\mathrm{t}-/ \mathrm{t}+$ \\
\hline & & & & & & $6 \mathrm{~A} 2-4$ & $5 A 2-4$ & 1.54 & 74.5 & -55.0 & $g+/ g-$ \\
\hline 7A1-1 & $6 \mathrm{~A} 1-1$ & -1.69 & 68.4 & 16.0 & $g+/ g+$ & $7 A 2-1$ & $6 \mathrm{~A} 2-1$ & -1.69 & -68.3 & -16.0 & $g-/ g-$ \\
\hline $7 A 1-2$ & $6 A 1-2$ & -0.41 & 85.2 & -68.3 & $g+/ g-$ & $7 A 2-2$ & $6 \mathrm{~A} 2-2$ & -0.41 & -85.6 & 68.3 & $g-/ g+$ \\
\hline \multirow[t]{2}{*}{ 7A1-3 } & $6 \mathrm{~A} 1-3$ & 0.00 & 159.7 & -164.0 & $t+/ t-$ & $7 A 2-3$ & $6 \mathrm{~A} 2-3$ & 0.00 & -159.7 & 164.0 & $t-/ t+$ \\
\hline & & & & & & $7 A 2-4$ & $6 \mathrm{~A} 2-4$ & 1.81 & 72.8 & -41.9 & $g+/ g-$ \\
\hline
\end{tabular}

of $\left(\mathrm{C}^{\alpha} \mathrm{C}-\mathrm{NC} \mathrm{C}^{\alpha}\right) /\left(\mathrm{CN}-\mathrm{C}^{\alpha} \mathrm{C}\right) /\left(\mathrm{NC}^{\alpha}-\mathrm{CN}\right)$ bonds. Second, the left- and right-handed rotational directions of the main chain were designated $+120^{\circ}$ and $-120^{\circ}$ dihedral angles $\left[\tau_{\alpha(\mathrm{n})}\right]$, respectively, which were repeated for the unit consisting of $\left(\mathrm{HN}-\mathrm{C}^{\alpha} \mathrm{CH}_{3}\right)$ bonds. Finally, the $\tau_{\mathrm{n}}$ values based on each value of $\left[\left(\chi_{n} / \varphi_{n} / \psi_{n}\right)_{x}\right]$ were determined. As an example of the model, the specific structure of the 4-mer is shown in Figure 2.

\section{Calculations}

For each model, conformational analyses were carried out using QCCs as implemented in the 'Gaussian 03W' software (Gaussian Inc.). ${ }^{13}$ In the structural optimizations, the restricted Hartree-Fock (RHF) and density functional theory (B3LYP) were used for the calculations along with the self-consistent field method. STO-3G, 6-31G and 6-31+G(d,p) (d, p: polarization, + : diffuse function) were used as the basis sets.

The convergent calculations were first carried out by using STO-3G and then 6-31G as the higher level basis set. First, the optimizations of the four types of 2-mer models mentioned above were carried out. In the designation of each model, the $\chi_{\mathrm{n}}$ values were fixed at $\pi$, and the $\varphi_{\mathrm{n}}\left(\varphi_{1}=\varphi_{2}\right)$ and $\psi_{\mathrm{n}}\left(\psi_{1}=\psi_{2}\right)$ values were designated at $\pi / 6$ intervals in four quadrants (164 types). Second, the optimizations of the 3-mer models were carried out based on the results of the converged conformers for the 2-mer. In the designations of the 3-mer models, the averaging values of $\chi_{n}, \varphi_{n}$ and $\psi_{n}$ of the conformers converged for 
Table 3 Energies $(\Delta \mathrm{E})$ and structures $\left(\varphi_{n} / \psi_{n}\right)_{x}$ of converged conformers for the 'methyl type' (by RHF/6-31G)

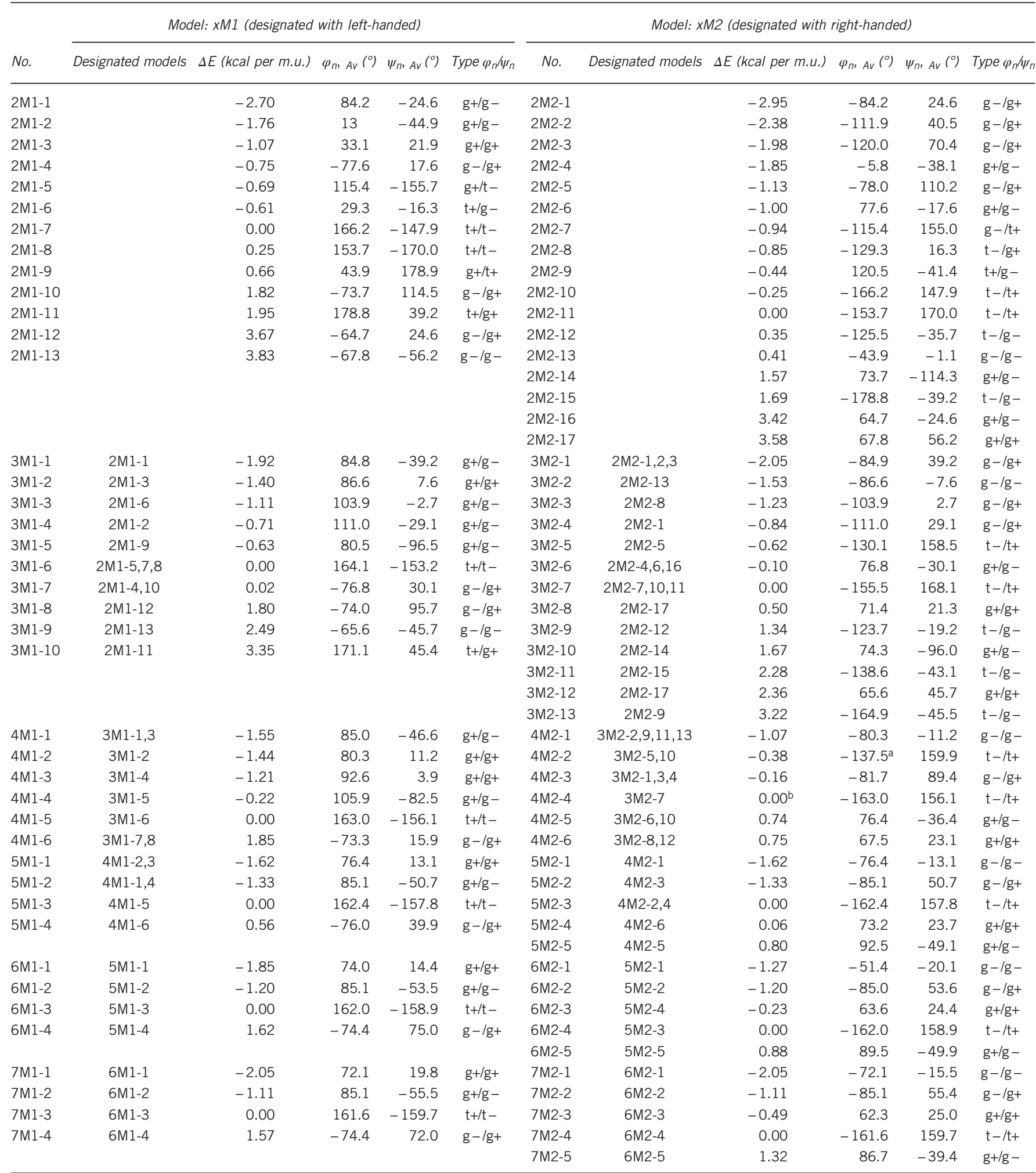

The $\varphi_{1}$ neighboring $\mathrm{N}$-end largely kinked to $-71.5^{\circ}$.

${ }^{b}$ As standard conformer of $\Delta \mathrm{E}, 4 \mathrm{M} 2-4$ (no kink type of $\varphi_{n}$ ) was used.

the 2-mer were used as the $\chi_{\mathrm{n}}, \varphi_{\mathrm{n}}$ and $\psi_{\mathrm{n}}$ values, respectively, for the 3-mer. The convergent calculations for the 4- to 7-mers were carried out in order using the same method as that employed for the 3-mer.
The formation energies (E: Hartree, 1 Hartree $=627.51 \mathrm{kcal} \mathrm{mol}^{-1}$, hereafter referred to as energy) and some structural parameters (that is, dihedral angles: $\tau$, chain length: L, dipole moment: $\mu$, and others) were recorded for the optimized structures (Figure 2). 
The conformations were specified based on the IUPAC rule ${ }^{14}$ as follows: $\tau_{\mathrm{n}}$ for trans $(\mathrm{t} \pm)$ and gauche $(\mathrm{g} \pm)$ are $\pm 120^{\circ}$ to $\pm 180^{\circ}$ and $\pm 0^{\circ}$ to $\pm 120^{\circ}$, respectively. The types of conformational distributions $\left(\varphi_{\mathrm{n}} / \psi_{\mathrm{n}}\right)_{\mathrm{x}}$ of the conformers were specified as follows: trans and gauche types are $(\mathrm{t} / \mathrm{t})$ and $(\mathrm{g} / \mathrm{g}, \mathrm{g} / \mathrm{t}$ or $\mathrm{t} / \mathrm{g})$, respectively.

\section{RESULTS AND DISCUSSION}

\section{Conformational convergence}

Four conformational convergent calculations of the alanine oligomer models for the 2-mer were performed: for the two end group types ('amide type' and 'methyl type') and for the left- and right-handed rotational directions of the main chain. The effect of the end group on the conformational properties of the peptide is important because the end group often affects the conformational changes (for example, transition and folding based on environmental changes (hydration $\left.{ }^{15}\right)$ ). To estimate the end group effect, one type of methyl amide group $\left(\mathrm{CH}_{3} \mathrm{NH}-\mathrm{CO}-\right)$ for the carboxyl end group (C-end) and two types of acetyl $\left(-\mathrm{NH}-\mathrm{COCH}_{3}\right)$ and methyl $\left(-\mathrm{NH}-\mathrm{CH}_{3}\right)$ groups for the amino end group ( $\mathrm{N}$-end) were prepared, as shown in Table 1. One of the reasons for preparing the methyl group for the N-end ('methyl type') is that this group may be more synthetically primitive than the acetyl group. In the calculations for the left- and right-handed rotational directions, $+120^{\circ}$ and $-120^{\circ}$, respectively, were designated as the dihedral angles $\left[\tau_{\alpha(\mathrm{n})}\right]$, which were repeated for the unit consisting of $\left(\mathrm{HN}-\mathrm{C}^{\alpha} \mathrm{CH}_{3}\right)$ bonds, as shown in Table 1 . In the designation of each model, the $\chi_{\mathrm{n}}$ values were fixed at $\pi$, and the $\varphi_{\mathrm{n}}\left(\varphi_{1}=\varphi_{2}\right)$ and $\psi_{\mathrm{n}}$ $\left(\psi_{1}=\psi_{2}\right)$ values were designated at $\pi / 6$ intervals in four quadrants (164 types). Here, $\chi_{\mathrm{n}}, \varphi_{\mathrm{n}}$, and $\psi_{\mathrm{n}}$ are dihedral angles $\left(\tau_{\mathrm{n}}\right)$ repeated for the unit consisting of $\mathrm{C}^{\alpha} \mathrm{C}-\mathrm{NC}{ }^{\alpha}, \mathrm{CN}-\mathrm{C}^{\alpha} \mathrm{C}$ and $\mathrm{NC}^{\alpha}-\mathrm{CN}$ bonds, respectively.

The results from the convergent calculations of the 'amide type' and 'methyl type' are shown in Tables 2 and 3, respectively. The results calculated for the models designated to be left- and right-handed are shown on the left and right side, respectively, of each table. In Tables 2 and 3, the energies $(\Delta \mathrm{E}, \mathrm{kcal}$ per m.u.) and dihedral angle distributions $\left[\left(\varphi_{n} / \psi_{n}\right)_{x}\right]$ of the $\mathrm{x}$-mers are shown. The $\Delta \mathrm{E}$ is the relative energy of the monomer unit to the energy of the trans type $\left[\left(\varphi_{n} / \psi_{n}\right)_{x}\right.$ : $\mathrm{t} / \mathrm{t}$ ] with calculated rotational direction.

In the convergent calculations for the 2 -mer models ( $4 \times 164$ types), many models converged to the same conformational isomer (hereafter referred to as conformers), leading to a smaller number of conformers, and the calculation could not be performed for several models because of the 'close contact' of atoms or 'link died' during the calculation. In the 'amide type', as shown in Table 2, the number of conformers designated to be left- and right-handed for the 2-mer were 11 and 9, respectively. In the 'methyl type', these values were 13 and 17, respectively, as shown in Table 3. There are more 'methyl type' conformers than 'amide type' conformers.

The convergent calculations for the 3-mer were carried out using the average value of $\chi_{\mathrm{n}}, \varphi_{\mathrm{n}}$ and $\psi_{\mathrm{n}}$ for the 2-mer converged conformers. As shown in Tables 2 and 3, the number of 3-mer conformers decreased compared with the number of 2-mer conformers. There were 5 'amide type' conformers for both the rightand left-handed models, and the number of left- and right-handed 'methyl type' conformers was 10 and 13 , respectively.

Table 4 Formation energies (E) of typical conformer types $(\varphi / \psi)$

\begin{tabular}{|c|c|c|c|c|c|c|c|c|c|c|c|}
\hline \multicolumn{7}{|c|}{ 'Amide type' } & \multicolumn{5}{|c|}{ 'Methyl type' } \\
\hline \multirow[b]{2}{*}{$\varphi h \psi$} & \multirow[b]{2}{*}{$x$} & \multicolumn{2}{|c|}{ Left-handed } & \multicolumn{2}{|c|}{ Right-handed } & \multirow[b]{2}{*}{$\begin{array}{c}E_{(R)}-E_{(L)} \\
\left(k c a l \mathrm{~mol}^{-1}\right)\end{array}$} & \multicolumn{2}{|c|}{ Left-handed } & \multicolumn{2}{|c|}{ Right-handed } & \multirow[b]{2}{*}{$\begin{array}{c}E_{(R)}-E_{(L)} \\
\left(\mathrm{kcal} \mathrm{mol}^{-1}\right)\end{array}$} \\
\hline & & $\left.\delta E_{m(L)}\right)^{a}(H F)$ & $\begin{array}{c}\Delta\left(\delta E_{m(L)}\right)^{\mathrm{b}} \\
\left(k c a l \mathrm{~mol}^{-1}\right)\end{array}$ & $\delta E_{m(R)^{\mathrm{a}}}(H F)$ & $\begin{array}{c}\Delta\left(\delta E_{m(R)}\right)^{\mathrm{b}} \\
\left(k c a l \mathrm{~mol}^{-1}\right)\end{array}$ & & $\left.\delta E_{m(L)}\right)^{a}(H F)$ & $\begin{array}{c}\Delta\left(\delta E_{m(L)}\right)^{\mathrm{b}} \\
\left(k c a l \mathrm{~mol}^{-1}\right)\end{array}$ & $\delta E_{m(R)^{\mathrm{a}}}(H F)$ & $\begin{array}{c}\Delta\left(\delta E_{m(R)}\right)^{\mathrm{b}} \\
\left(k c a l \mathrm{~mol}^{-1}\right)\end{array}$ & \\
\hline & 2 & - & & - & & 0.00 & - & & - & & 0.50 \\
\hline & 3 & -245.7443 & - & -245.7443 & - & 0.00 & -245.7439 & - & -245.7470 & - & -1.51 \\
\hline$t+/ t-$ & 4 & -245.7443 & 0.00 & -245.7443 & 0.00 & 0.00 & -245.7443 & -0.25 & -245.7443 & 1.69 & -1.51 \\
\hline $\mathrm{t}-/ \mathrm{t}+$ & 5 & -245.7443 & 0.00 & -245.7443 & 0.00 & 0.00 & -245.7443 & 0.00 & -245.7419 & 1.51 & 0.00 \\
\hline \multirow[t]{5}{*}{$(\beta)$} & 6 & -245.7443 & 0.00 & -245.7443 & 0.00 & 0.00 & -245.7443 & 0.00 & -245.7443 & -1.51 & 0.00 \\
\hline & 7 & -245.7444 & -0.06 & -245.7444 & -0.06 & 0.00 & -245.7443 & 0.00 & -245.7443 & 0.00 & 0.00 \\
\hline & & & $A v=-0.02$ & & $A v=-0.02$ & & & $A v=-0.06$ & & $A v=0.42$ & \\
\hline & 2 & - & & - & & 0.00 & - & & - & & 0.00 \\
\hline & 3 & -245.7449 & - & -245.7449 & - & 0.00 & -245.7445 & - & -245.7445 & - & 0.00 \\
\hline$g+/ g-$ & 4 & -245.7449 & 0.00 & -245.7449 & 0.00 & 0.00 & -245.7450 & -0.31 & -245.7450 & -0.31 & 0.00 \\
\hline \multirow{6}{*}{$\begin{array}{l}g-/ g+ \\
\text { (p) }\end{array}$} & 5 & -245.7451 & -0.13 & -245.7451 & -0.13 & 0.00 & -245.7450 & 0.00 & -245.7450 & 0.00 & 0.00 \\
\hline & 6 & -245.7451 & 0.00 & -245.7451 & 0.00 & 0.00 & -245.7452 & -0.31 & -245.7452 & -0.31 & 0.00 \\
\hline & 7 & -245.7453 & -0.13 & -245.7453 & -0.13 & 0.00 & -245.7452 & 0.00 & -245.7452 & 0.00 & 0.00 \\
\hline & & & $A v=-0.07$ & & $A v=-0.07$ & & & $A v=-0.16$ & & $A v=-0.16$ & \\
\hline & 2 & - & & - & & 0.00 & - & & - & & 3.45 \\
\hline & 3 & -245.7463 & - & -245.7463 & - & 0.00 & -245.7472 & - & -245.7527 & - & 0.00 \\
\hline \multirow{4}{*}{$\begin{array}{l}g+/ g+ \\
g-/ g- \\
(\alpha)\end{array}$} & 4 & -245.7479 & -1.00 & -245.7479 & -1.00 & 0.00 & -245.7468 & 0.25 & -245.7468 & 3.70 & 0.00 \\
\hline & 5 & -245.7488 & -0.56 & -245.7488 & -0.56 & 0.00 & -245.7480 & -0.75 & -245.7480 & -0.75 & 0.00 \\
\hline & 6 & -245.7493 & -0.31 & -245.7493 & -0.31 & 0.00 & -245.7491 & -0.69 & -245.7435 & 2.82 & 3.51 \\
\hline & 7 & -245.7499 & $\begin{array}{c}-0.38 \\
A v=-0.56\end{array}$ & -245.7499 & $\begin{array}{c}-0.38 \\
A v=-0.56\end{array}$ & 0.00 & -245.7551 & $\begin{array}{c}-3.77 \\
A v=-1.24\end{array}$ & -245.7551 & $\begin{array}{c}-7.28 \\
A v=-0.38\end{array}$ & 0.00 \\
\hline
\end{tabular}

Abbreviation: HF, Hartree-Fock.

${ }^{a} \delta E_{m(L)}=E_{(L),(x)}-E_{(L),(x-1)}, \delta E_{m(R)}=E_{(R),(x)}-E_{(R),(x-1)}$.

${ }^{2} \delta E_{m(L)}=E_{(L),(x)} E_{(L),(x-1),} \delta E_{m(R)}=E_{(R),(x)}-E_{(R),(x-1) .}$
${ }^{b} \Delta\left(\delta E_{m(L)}\right)=\delta E_{m(L),(x)} \delta E_{m(L),(x-1),} \Delta\left(\delta E_{m(R)}\right)=\delta E_{m(R),(x)}-\delta E_{m(R),(x-1) .}$ 
The convergent calculations for the 4- to 7-mer were carried out in order by using the same methods as those used for the 3-mer. As shown in Tables 2 and 3, the number of conformers decreased as the monomer unit number ( $\mathrm{x}$ ) increased. The number of 'amide type' conformers with left- and right-handed conformations did not change for chains longer than 4-mer and 5-mer, respectively. The number of 'methyl type' conformers did not change for chains longer than the 5-mer.

As shown in Tables 2 and 3, the conformers of the 4- to 7-mer converged to three $\varphi / \psi$ types as follows: helix $(\mathrm{g}+/ \mathrm{g}+$ or $\mathrm{g}-/ \mathrm{g}-$, hereafter referred to as $\alpha$-helix), extended helix-like ( $\mathrm{g}+/ \mathrm{g}-$ or $\mathrm{g}-/ \mathrm{g}$ + , hereafter referred to as polyproline II-like or PPII-like), and extended $(\mathrm{t}+/ \mathrm{t}-$ or $\mathrm{t}-/ \mathrm{t}+$, hereafter referred to as $\beta$-extended $)$ in order of decreasing energy. These results support the ' $\alpha$-helix preferable' of polyalanine. ${ }^{16,17}$ In the conformers smaller than the 3 -mer, PPII-like (or $\beta$-extended) is more stable than the $\alpha$-helix. This result indicates that the main conformation is affected by the monomer unit number during chain propagation. For the conformers designated as left-handed $\left[+120^{\circ}\right.$ of $\left.\tau_{\alpha(\mathrm{n})}\right]$, the left-handed rotational directions $(\mathrm{t}+/ \mathrm{t}-, \mathrm{g}+/ \mathrm{g}-$, or $\mathrm{g}+/ \mathrm{g}+)$ are more stable than the righthanded ones $(\mathrm{t}-/ \mathrm{t}+, \mathrm{g}-/ \mathrm{g}+$, or $\mathrm{g}-/ \mathrm{g}-)$ for each end group type. However, for the conformers designated as right-handed [ $-120^{\circ}$ of $\tau_{\alpha}$ (n)], the right-handed rotational directions are more stable than the left-handed one for each end group type. The effects of the rotational directions on the $\varphi / \psi$ types were determined. In the PPII-like conformers of the 'amide type' over 4-mer, as shown in Table 2, the models designated as right-handed converged to left-handed models (4A2-5, 5A2-4, 6A2-4, 7A2-4: $\mathrm{g}+\mathrm{g}-$ ), resulting in more stable right-handed models $(\mathrm{g}-/ \mathrm{g}+)$ even though the models designated as left-handed converged only to left-handed models. For the 'methyl type', as shown in Table 3, the $\alpha$-helix over 4-mer designated as right-handed converged to the left-handed models (4M2-6, 5M2-4, 6M2-3, 7MA2-3: $\mathrm{g}+/ \mathrm{g}+$ ), resulting in more stable right-handed models $(\mathrm{g}-/ \mathrm{g}-)$ even though the models designated as left-handed converged only to left-handed models. These results may be related to the method of designation for the rotational directions but the details remain unclear.

The effects of the calculation methods on the optimizations were examined by using B3LYP/6-31+G (d, p) for the left-handed 'amide type' 5-mer (5A1-1, 5A1-2 and 5A1-3 in Table 2). The $\varphi / \psi$ types were not affected by the calculation method, and the energy levels of the three conformers $(\Delta \mathrm{E}:-0.48,-0.5$ and 0$)$ were nearly the same using the RHF/6-31G methods.

\section{Energy analyses}

In this section, the energies of the three conformer types (that is, $\beta$-extended, PPII-like and $\alpha$-helix) during chain propagation are discussed.

In Table 4, the formation energies (E) of the three conformer types of the 2- to 7-mer are shown. All of the $\mathrm{E}_{(\mathrm{L})}$ and $\mathrm{E}_{(\mathrm{R})}$ values are provided in the supporting information (Supplementary Table S1). For the 'amide type', no energy differences were observed between the left- and right-handed models (that is, the values of $\mathrm{E}_{(\mathrm{R})}-\mathrm{E}_{(\mathrm{L})}$ are zero). However, for the 'methyl type', the energy values of the left- and right-handed are different for the 2-, 3- and 4-mer with $\beta$-extended conformations and the 2- and 6-mer with $\alpha$-helix conformations. These results indicate that the conformational structures of the 'methyl type' are different during chain propagation compared with those of the 'amide type'.

The energy changes with an increase in the monomer unit number $(\mathrm{x}), \delta \mathrm{E}_{\mathrm{m}}(\mathrm{HF})$ and the differences in $\delta \mathrm{E}_{\mathrm{m}}$ between $\mathrm{x}$-mer and $(\mathrm{x}-1)$ mer $\left(\Delta\left(\delta \mathrm{E}_{\mathrm{m}}\right)\left(\mathrm{kcal} \mathrm{mol}^{-1}\right)\right)$ are listed in Table 4 . The $\Delta\left(\delta \mathrm{E}_{\mathrm{m}}\right)$ values
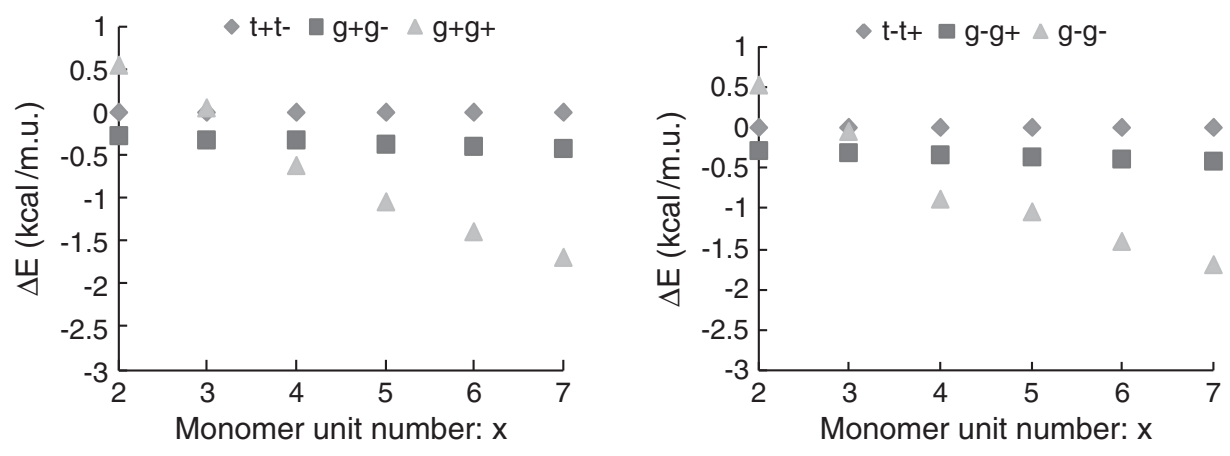

xA1 (left-handed "amide type")

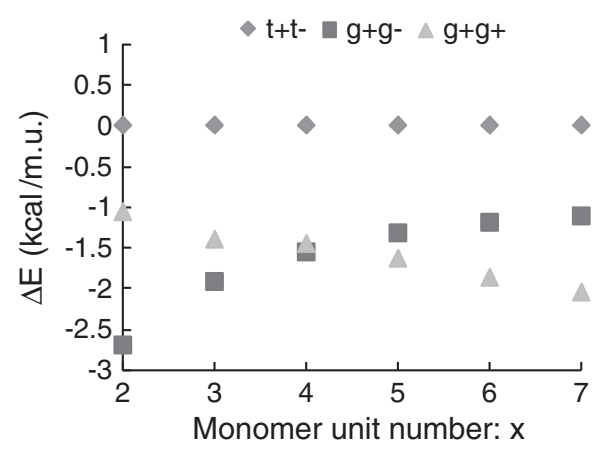

xA2 (right-handed "amide type")

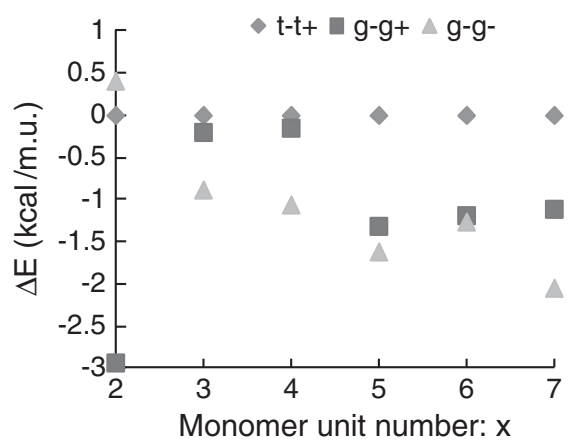

xM1 (left-handed "methyl type")

xM2 (right-handed "methyl type")

Figure 1 Relationships between the energies ( $\Delta \mathrm{E}$ : $\mathrm{kcal}$ per m.u.) and monomer unit numbers $(\mathrm{x})$ of conformers. A full color version of this figure is available at Polymer Journal online. 


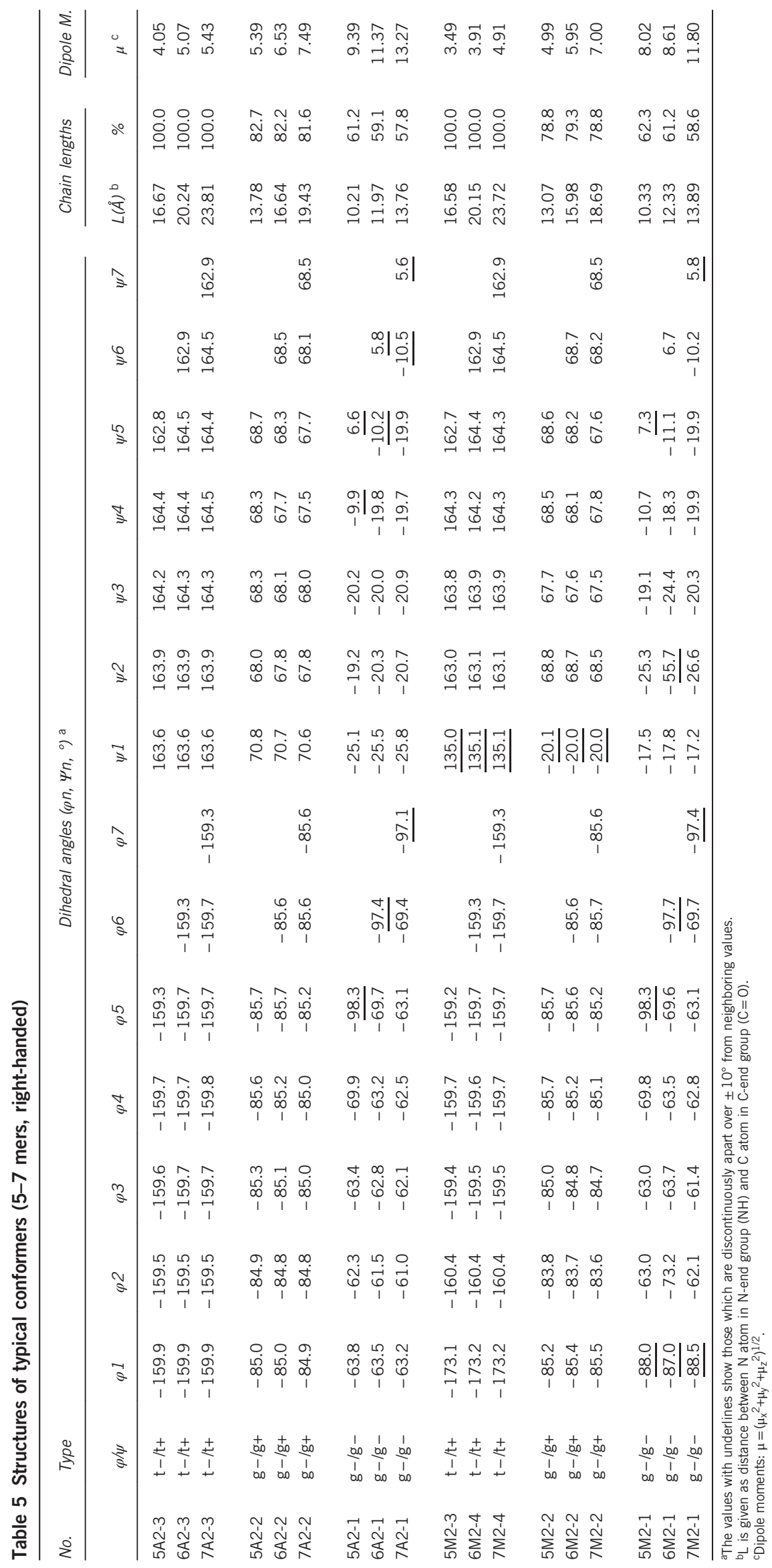


of the $\beta$-extended conformers are negligible, except for the righthanded 'methyl type'. The $\Delta\left(\delta \mathrm{E}_{\mathrm{m}}\right)$ values of the PPII-like and $\alpha$-helix conformation of the 'amide type' are -0.13 to 0.00 and -1.00 to -0.31 , respectively. The $\Delta\left(\delta \mathrm{E}_{\mathrm{m}}\right)$ values of the PPII-like conformations are not very large. However, the $\Delta\left(\delta \mathrm{E}_{\mathrm{m}}\right)$ values of the $\alpha$ type are clearly negative, indicating that this type of oligomer is more stable as $\mathrm{x}$ increases because of the intramolecular hydrogen bonds between the distant monomer units.

In Figure 1, the energy differences $(\Delta \mathrm{E})$ between PPII-like and $\beta$-extended and between $\alpha$-helix and $\beta$-extended are plotted as a function of $\mathrm{x}$. The $\Delta \mathrm{E}$ values for the $\alpha$-helix conformations decrease as $\mathrm{x}$ increases independent of the rotational directions and end group types. However, the $\Delta \mathrm{E}$ values of the PPII-like conformations do not change with $\mathrm{x}$ in the 'amide type', and in the left-handed 'methyl type', the $\Delta \mathrm{E}$ values increase as $\mathrm{x}$ increases. The $\Delta \mathrm{E}$ values of the PPII-like conformations of the right-handed 'methyl type' are scattered as a function of $\mathrm{x}$ because of the large $\Delta\left(\delta \mathrm{E}_{\mathrm{m}}\right)$ values of the $\beta$-extended

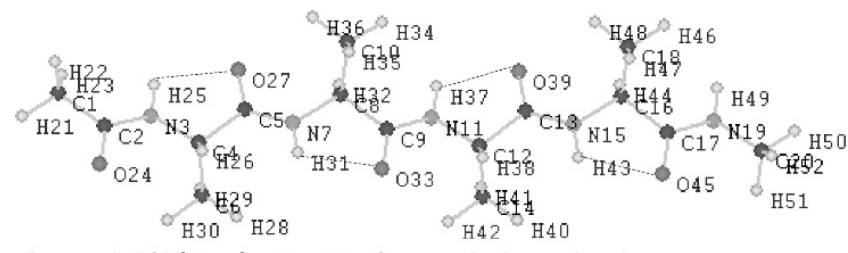

$\beta$-extended ( $\phi / \Psi=t-/ t+$, No. 4A2-3), - - - - hydrogen bonds

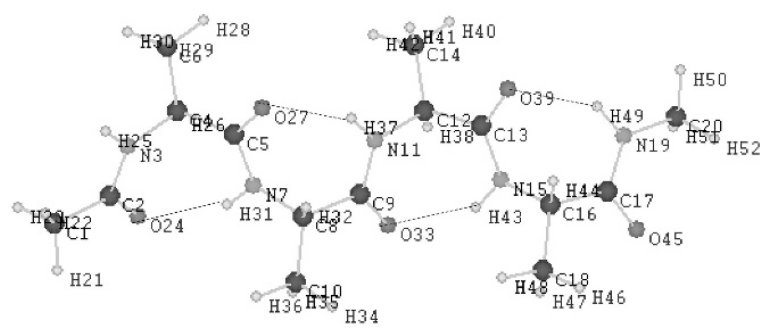

PPII-like $(\phi / \Psi=g-/ g+$, No. 4A2-2), - . - - hydrogen bonds

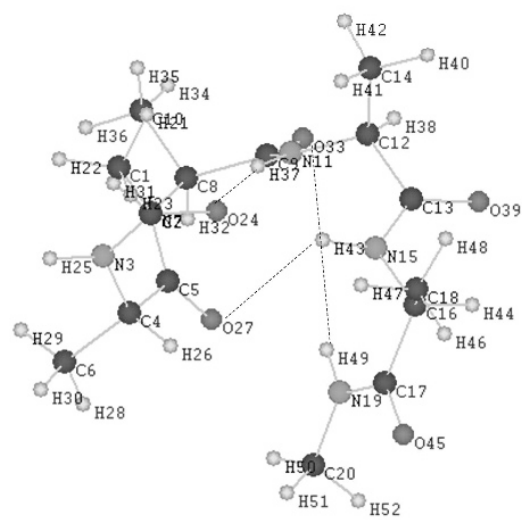

$\alpha$-helix $(\phi / \Psi=\mathrm{g}-/ \mathrm{g}-$, No. 4A2-1, - . - - hydrogen bonds

Figure 2 Examples of the structure and hydrogen bonds of the 4-mer (righthanded 'amide type'). In the $\beta$-extended conformer, each structural parameter is given as follows: $\chi_{1}$ : C1C2-N3C4; $\varphi_{1}$ :C2N3-C4C5; $\psi_{1}$ :N3C4C5N7; $\tau_{\alpha 1}: \mathrm{H} 25 \mathrm{~N} 3-\mathrm{C} 4 \mathrm{C} 6$; and $\mathrm{L}: \mathrm{d}_{\mathrm{N} 3-\mathrm{C} 17}$. Each strong hydrogen bond is shown as follows: $\beta$-extended: $d_{H 25-027}(2.17 \AA), d_{H 31-033}(2.16 \AA), d_{H 37-039}$ $(2.15 \AA)$ and $\mathrm{d}_{\mathrm{H} 43-045}=(2.16 \AA)$; PPII-like: $\mathrm{d}_{\mathrm{H} 31-024}(2.10 \AA), \mathrm{d}_{\mathrm{H} 37-027}$ $(2.09 \AA), \quad d_{\text {H43-033 }}(2.10 \AA)$ and $\quad d_{H 49-039}=(2.11 \AA) ; \quad$ and $\alpha$-helix: $\mathrm{d}_{\mathrm{H} 37-024}(2.17 \AA), \mathrm{d}_{\mathrm{H} 43-027}(2.24 \AA)$ and $\mathrm{d}_{\mathrm{H} 49-033}(2.24 \AA)$, refer to Table 9. A full color version of this figure is available at Polymer Journal online. conformations (see Table 4). These results indicate that the alanine oligomer is ' $\alpha$-helix preferable' during chain propagation.

\section{Structure analyses}

In this section, the structural parameters and intramolecular hydrogen bonding in the converged conformers are discussed.

Structure parameters. The structural parameters of the three types of right-handed 5- to 7-mers are shown in Table 5 because all of the parameters did not changed because of the rotational directions or end group type. The $\chi_{n}$ values are in the range of $\pm 167^{\circ}$, which is nearly equal to $\pi$, because of the conjugation property of the peptide group (CO-NH). All of the $\beta$-extended conformation of the 'amide type' had nearly equal $\varphi$ and $\psi$ values of approximately $-160^{\circ}$ and $164^{\circ}$, respectively. The PPII-like conformations of the 'amide type' had nearly equal $\varphi$ and $\psi$ values of approximately $-85^{\circ}$ and $68^{\circ}$, respectively, irrespective of the length and position. The $\alpha$-helix conformations had nearly equal $\varphi$ and $\psi$ values of approximately $-63^{\circ}$ and $-20^{\circ}$, respectively, except for those one or two monomer units from the carbonyl terminal group. These results are underline in Table 5 and are because of intramolecular hydrogen bonds. The methyl type oligomers exhibited nearly the same tendency except that they had slightly different $\varphi$ and $\psi$ values one or two units from the amide terminal group in addition to the carbonyl terminal group. The main chain of the 'methyl type' largely kinks at the N-end. This kink may be because of the lack of a peptide group at the $\mathrm{N}$-end of the 'methyl type'. We previously reported ${ }^{9}$ that in the conformational calculations for isotactic methyl methacrylate oligomer models (3- to 7-mer) using QCCs, some stable conformers kinked at the end of the chains in addition to those without kinks, and these kinked structures are consistent with those observed in this study. The results reported in Tables 2 and 3 where the number of 'methyl type' conformers is
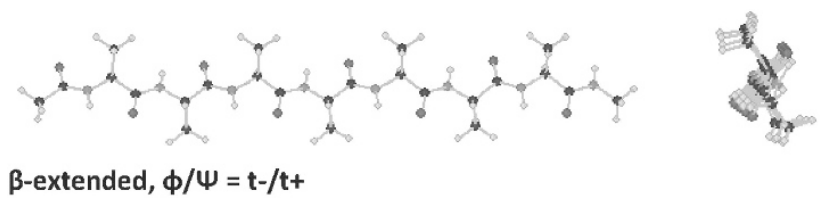

$\beta$-extended, $\phi / \Psi=\mathrm{t}-/ \mathrm{t}+$
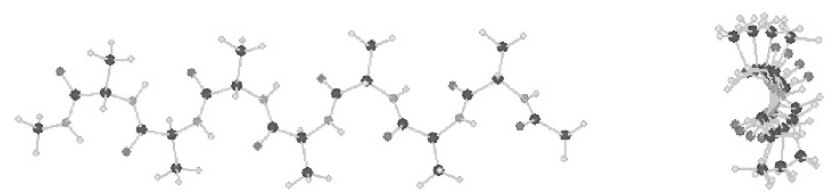

PPII-like, $\phi / \Psi=\mathrm{g}-/ \mathrm{g}+$
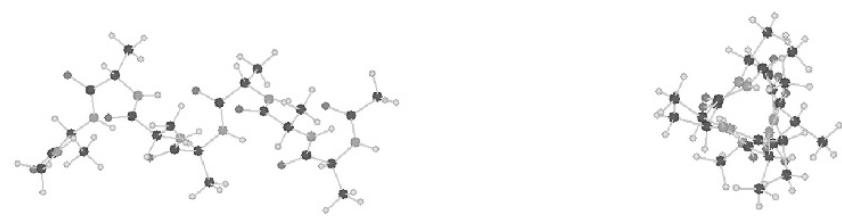

$\alpha$-helix, $\phi / \Psi=\mathrm{g}$ - $/ \mathrm{g}$ -

Figure 3 Right-handed structures optimized for the 'amide type' 7-mer. Left and right figures show the stereo oblique and chain axis projections, respectively. Each averaged value of $\chi / \varphi / \psi$ is shown as follows: $(\mathrm{t}+/ \mathrm{t}-/ \mathrm{t}+)$ : 176.6/-159.7/164.0; (t-/g-/g+): $-173.4 /-85.6 / 68.3$; and (t-/g-/g-) type: $-173.8,-68.3 /-16.0$. A full color version of this figure is available at Polymer Journal online. 
Table 6 Comparison of $\varphi / \psi$ values $\left(^{\circ}\right)$ calculated for 7 -mer with those values reported for alanine oligomers

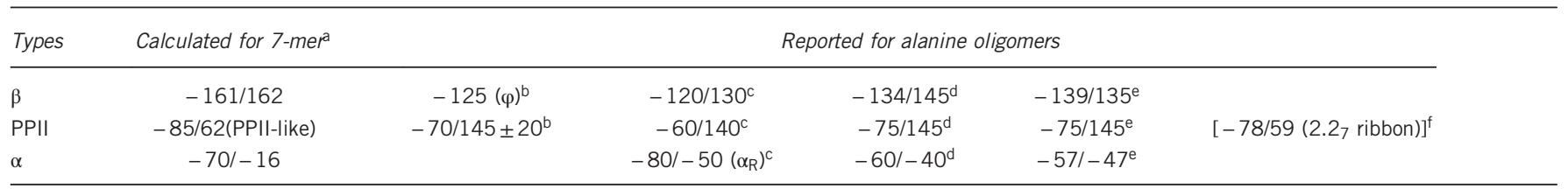

aThe values of $\varphi / \psi$ were averaged for each $\varphi$ and $\psi$ value of right-handed 'amide type', by RHF/6-31G. Refer the foot note of Figure 3 .

bShi, et al. ${ }^{3}$, by $\mathrm{H}^{1}-\mathrm{NMR}\left(\right.$ in $\left.\mathrm{D}_{2} \mathrm{O}\right), \mathrm{x}=7$.

${ }^{\mathrm{c}} \mathrm{Graf}$, et al. ${ }^{6}$, by MD/NMR, $\mathrm{x}=3-7$.

'Mirkin, et al. 7 , by QCC, $x=1-7$.

${ }^{\text {e } K e n t s i s, \text { et al. }}{ }^{8}$, by MD and Monte Carlo, $x=7$ and 14

$\mathrm{f}$ Listed as one of the $\varphi / \psi$ type of peptides. 18

Table 7 Examinations of PPII conformation (model: left- and right-handed 'amide type' of 5-mer)

\begin{tabular}{|c|c|c|c|c|c|}
\hline \multirow[b]{2}{*}{ Methods of calculations (designated model)a } & \multirow[b]{2}{*}{ Formation energies $E$ (HF) } & \multicolumn{4}{|c|}{ Dihedral distributions: $\left(\varphi_{n} / \psi_{n}\right)_{5},\left(^{\circ}\right)$} \\
\hline & & $\chi_{n, A V}(-175)$ & $\varphi_{n, A V}(-60)$ & $\psi_{n, A V}(140)$ & $\varphi$ h types $(g-/ t+, P P I I)$ \\
\hline \multicolumn{6}{|l|}{ For the model designated with left-handed } \\
\hline A RHF/STO-3G & -1457.4446 & 158.0 & -57.8 & -174.0 & $g-/ t-$ \\
\hline $\mathrm{B} \mathrm{A} \rightarrow \mathrm{RHF} / 6-31 \mathrm{G}$ & -1475.6049 & -175.3 & -74.6 & 55.3 & g-/g+ (PPII-like) \\
\hline$C A \rightarrow B 3 L Y P / 6-31 G$ & -1484.7280 & -174.8 & -71.7 & 55.3 & $g-/ g+(P P I I-l i k e)$ \\
\hline$D A \rightarrow B 3 L Y P / 6-31+G(d, p)$ & -1485.2784 & -174.5 & -72.9 & 53.2 & $g-/ g+(P P I I-l i k e)$ \\
\hline $\mathrm{E} R \mathrm{RH} / 6-31 \mathrm{G}^{\mathrm{b}}$ & -1475.6049 & -174.7 & -74.6 & 55.3 & $g-/ g+(P P I I-l i k e)$ \\
\hline$B(5 A 1-3)$ & -1475.6177 & -176.9 & 159.6 & -163.8 & $\mathrm{t}+/ \mathrm{t}-(\beta$-extended $)$ \\
\hline$B(5 A 1-2)$ & -1475.6206 & 174.6 & 85.3 & -68.8 & g+/g- (PPII-like) \\
\hline \multicolumn{6}{|l|}{ For the model designated with right-handed } \\
\hline A RHF/STO-3G & -1457.4571 & 160.2 & -86.8 & 159.6 & $g-/ t+(P P I I)$ \\
\hline $\mathrm{B} A \rightarrow \mathrm{RHF} / 6-31 \mathrm{G}$ & -1475.6177 & 176.7 & -159.6 & 163.8 & $\mathrm{t}-/ \mathrm{t}+(\beta$-extended $)$ \\
\hline$C A \rightarrow B 3 L Y P / 6-31 G$ & -1484.7324 & 177.1 & -163.4 & 169.1 & $\mathrm{t}-/ \mathrm{t}+(\beta$-extended $)$ \\
\hline$D A \rightarrow B 3 L Y P / 6-31+G(d, p)$ & -1485.2890 & 175.3 & -156.4 & 162.7 & $\mathrm{t}-/ \mathrm{t}+(\beta$-extended $)$ \\
\hline E RHF/6-31G & -1475.6163 & -178.7 & -144.6 & 155.5 & $\mathrm{t}-/ \mathrm{t}+(\beta \text {-extended })^{\mathrm{c}}$ \\
\hline$B(5 A 2-3)$ & -1475.6177 & 176.7 & -159.6 & 163.8 & $\mathrm{t}-/ \mathrm{t}+(\beta$-extended $)$ \\
\hline$B(5 A 2-2)$ & -1475.6206 & -173.6 & -85.3 & 68.8 & g-/g+ (PPII-like) \\
\hline
\end{tabular}

aFrom. ${ }^{6}$

bCalculated without through RHF/STO-3G.

${ }^{\mathrm{c}}$ Kinked in C-end $\left(\varphi 5=-85.7^{\circ}, \psi 5=74.9^{\circ}\right)$.

larger than the number of 'amide type' conformers, are related to these results, and therefore, the 'methyl type' had many local minimums.

As shown in Table 5, the chain lengths of the PPII-like and $\alpha$-helix conformations are approximately 20 and $40 \%$, respectively, smaller than the chain lengths of the $\beta$-extended conformations. The dipole moments of the PPII-like and $\alpha$-helix conformations are approximately 40 and $140 \%$, respectively, larger than the dipole moments of the $\beta$-extended conformations. These results indicate that the intramolecular interactions decrease in the order of $\alpha$-helix, PPII-like and extended chains.

Figures 2 and 3 show the structures of the right-handed 'amide type' 4- and 7-mers, respectively. As shown in Figures 2 and 3 as well as Table 5 , the calculated $\beta$-extended $(\mathrm{t}-/ \mathrm{t}+)$ and $\alpha$-helix $(\mathrm{g}-/ \mathrm{g}-)$ correspond to the parallel $\beta$-extended and the right-handed $\alpha$-helix $\alpha_{R}$-helix, numbers of amino acid residue in one turn: 3.6, whose structures are typical second-order peptide structures. The PPII-like $(\mathrm{g}-/ \mathrm{g}+)$ calculated shows an extended helical structure and is like the PPII $(\mathrm{g}-/ \mathrm{t}+$, extended helix-like), respectively, which is a typical second-order structure of peptides. The PPII-like conformer is considered to be a 2.27 ribbon $(\mathrm{g}-/ \mathrm{g}+)^{18}$ because the numbers of amino acid residue in one turn and the atoms in the structure cyclized by a hydrogen bond are close to those of the 2.27 ribbon.
Table 6 provides a comparison of the $\varphi / \psi$ values of 7 -mers with those reported for alanine oligomers. The $\varphi / \psi$ values of the $\beta$-extended and $\alpha$-helix conformations in this study are nearly the same as those previously reported. However, the PPII-like conformation is different from the previously reported PPII. Shi et al. ${ }^{3}$ reported $125^{\circ}<\psi<165^{\circ}$ when $\varphi=-70^{\circ}$ for the PPII conformation of an alanine heptamer based on $\mathrm{H}^{1}$ NMR (in $\mathrm{D}_{2} \mathrm{O}$ ) measurements. Graf et al. ${ }^{6}$ calculated the $\varphi$ and $\psi$ values of the PPII conformer of the alanine trimer by using MD and obtained $-90^{\circ}<\varphi<-25^{\circ}$ and $80^{\circ}<\psi<160^{\circ}$ based on the Ramachandran probability distributions. Based on these results, the $\varphi / \psi$ values were determined to be $-60^{\circ} /$ $140^{\circ}$ for the PPII conformer of alanine oligomers. Mirkin et al. ${ }^{7}$ reported the $\varphi / \psi$ values of $-75^{\circ} / 145^{\circ}$ for the PPII conformer optimized using ab initio calculations (that is, B3LYP/6-31+ $\mathrm{G}^{*}$ ). However, in this study, the PPII conformer was not obtained for the 3-mer to 7-mer even though it was obtained for the 2-mer, as shown in Tables 2 and 3. The PPII type models (2A1-10: $\mathrm{g}-\mathrm{t}+$, 2M1-5: $\mathrm{g}+\mathrm{t}-$, and 2M2-7: $\mathrm{g}-\mathrm{t}+$ ) of the 3-mer (3A1-4, 3M1-6, and $3 \mathrm{M} 2-7)$ became PPII-like $(\mathrm{g}-/ \mathrm{g}+)$ or $\beta$-extended $(\mathrm{t}+/ \mathrm{t}-, \mathrm{t}-/ \mathrm{t}+)$ conformers.

The PPII conformations were calculated using the left- and righthanded 'amide type' models of the 5 -mer with $\varphi$ and $\psi$ values of $-60^{\circ}$ and $140^{\circ}$, respectively, for the PPII type ${ }^{6}$ using (A) RHF/STO-3G, (B) 
Table 8 Intramolecular hydrogen bonds in left-handed conformers of 'amide type' (No: $x A 1-), \mathrm{CH}_{3} \mathrm{CO}^{0}-\left[\mathrm{NH}^{1} \mathrm{C}^{\alpha}\left(\mathrm{CH}_{3}\right) \mathrm{CO}^{1}-\mathrm{NH}^{2} \mathrm{C}^{\alpha}\left(\mathrm{CH}_{3}\right) \mathrm{CO}^{2}-\right.$ $\left.\mathrm{NH}^{3} \mathrm{C}^{\alpha}\left(\mathrm{CH}_{3}\right) \mathrm{CO}^{3}-\mathrm{NH}^{4} \mathrm{C}^{\alpha}\left(\mathrm{CH}_{3}\right) \mathrm{CO}^{4}-\mathrm{NH}^{5} \mathrm{C}^{\alpha}\left(\mathrm{CH}_{3}\right) \mathrm{CO}^{5}\right]-\mathrm{NH}^{6} \mathrm{CH}_{3}$

\begin{tabular}{|c|c|c|c|c|}
\hline \multirow[b]{2}{*}{ No. } & \multirow[b]{2}{*}{ Type of $\varphi_{n} / \psi_{n}$} & \multicolumn{3}{|c|}{ Distances between $\mathrm{H}$ and $\mathrm{O}$ atoms $: d_{H-O}(\AA, \leqslant 3.0)$} \\
\hline & & Pattern ' $A$ ' & Pattern ' $B$ ' & Pattern 'C' \\
\hline $2 A 1-2$ & $\beta, \mathrm{t}+/ \mathrm{t}-$ & $\mathrm{d}_{\mathrm{H} 1-01}(2.18), \mathrm{d}_{\mathrm{H} 2-02}(2.17)$ & & \\
\hline $2 \mathrm{~A} 1-1$ & PPII-like, g+/g- & & $\mathrm{d}_{\mathrm{H} 2-\mathrm{OO}}(2.14), \mathrm{d}_{\mathrm{H} 3-01}(2.12)$ & \\
\hline $2 \mathrm{~A} 1-4$ & $\alpha, \mathrm{g}+/ \mathrm{g}+$ & & $\mathrm{d}_{\mathrm{H} 2-\mathrm{OO}}(2.98)$ & $\mathrm{d}_{\mathrm{H} 3-00}(2.18)^{\mathrm{a}}$ \\
\hline $3 A 1-2$ & $\beta, \mathrm{t}+\mathrm{t}-$ & $\mathrm{d}_{\mathrm{H} 1-01}(2.18), \mathrm{d}_{\mathrm{H} 2-\mathrm{O} 2}(2.16), \mathrm{d}_{\mathrm{H} 3-\mathrm{O}}(2.16)$ & & \\
\hline $3 A 1-1$ & PPII-like, g+/g- & & $\mathrm{d}_{\mathrm{H} 2-\mathrm{OO}}(2.11), \mathrm{d}_{\mathrm{H} 3-\mathrm{O} 1}(2.11), \mathrm{d}_{\mathrm{H} 4-02}(2.12)$ & \\
\hline $3 A 1-3$ & $\alpha, g+/ g+$ & & $\mathrm{d}_{\mathrm{H} 2-\mathrm{OO}}(3.00), \mathrm{d}_{\mathrm{H} 3-01}(3.00)$ & $\mathrm{d}_{\mathrm{H} 3-00}(2.17)^{\mathrm{b}}, \mathrm{d}_{\mathrm{H} 4-01}(2.26)^{\mathrm{b}}$ \\
\hline $4 \mathrm{~A} 1-3^{\mathrm{C}}$ & $\beta, \mathrm{t}+/ \mathrm{t}-$ & $\begin{array}{l}d_{\mathrm{H} 1-01}(2.17), d_{\mathrm{H} 2-02}(2.16) \\
d_{\mathrm{H} 3-03}(2.15), d_{\mathrm{H}-04}(2.16)\end{array}$ & & \\
\hline $4 A 1-2^{c}$ & PPII-like, g+/g- & $\mathrm{d}_{\mathrm{H} 2}$ & $(2.10), d_{\mathrm{H} 3-01}(2.09), d_{H 4-02}(2.10), d_{H 5-03}(2.11)$ & \\
\hline $4 \mathrm{~A} 1-1^{\mathrm{C}}$ & $\alpha, \mathrm{g}+/ \mathrm{g}+$ & & $\mathrm{d}_{\mathrm{H} 2-00}(2.99), \mathrm{d}_{\mathrm{H} 3-01}(3.00)$ & $\begin{array}{c}d_{H 3-00}(2.17) b, d_{H 4-01}(2.24)^{b} \\
d_{H 5-02}(2.24)^{b}\end{array}$ \\
\hline $5 A 1-3$ & $\beta, t+/ t-$ & $\begin{array}{c}d_{\mathrm{H} 1-01}(2.17), d_{\mathrm{H} 2-02}(2.16), d_{\mathrm{H} 3-03}(2.15) \\
d_{\mathrm{H} 4-04}(2.15), d_{\mathrm{H} 5-05}(2.15)\end{array}$ & & \\
\hline $5 A 1-2$ & PPII-like, g+/g- & & $\begin{array}{c}d_{H 2-00}(2.10), d_{H 3-01}(2.08), d_{H 4-02}(2.08), \\
d_{H 5-03}(2.10), d_{H 6-04}(2.11) \\
d_{H 2-00}(3.00), d_{H 3-01}(2.99)\end{array}$ & \\
\hline $5 A 1-1$ & $\alpha, g+/ g+$ & & 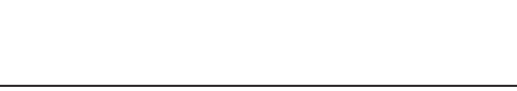 & $\begin{array}{l}\mathrm{d}_{\mathrm{H} 3-00}(2.14)^{\mathrm{b}}, \mathrm{d}_{\mathrm{H} 4-01}(2.24)^{\mathrm{b}}, \\
\mathrm{d}_{\mathrm{H} 5-02}(2.21)^{\mathrm{b}}, \mathrm{d}_{\mathrm{H} 6-03}(2.22)^{\mathrm{b}} \\
\end{array}$ \\
\hline \multicolumn{5}{|c|}{$\begin{array}{l}\left.{ }^{a} n_{h} \text { (Numbers of atoms in structure cyclized by hydrogen bond }\right)=10 \text {. } \\
{ }^{b} n_{h}=12 .{ }^{.} \text {Refer Figure } 2 .\end{array}$} \\
\hline & & \multicolumn{3}{|c|}{ Distances between $H$ and $O$ atoms : $d_{H-O}(\AA, \leqslant 3.0)$} \\
\hline No. & Type: $\varphi_{n} / \psi_{n}$ & Pattern 'A' & Pattern ' $B$ ' & Pattern ' $C$ ' \\
\hline 2M1-7 & $\beta, \mathrm{t}+/ \mathrm{t}-$ & $\mathrm{d}_{\mathrm{H} 1-01}(2.42), \mathrm{d}_{\mathrm{H} 2-02}(2.19)$ & & \\
\hline $2 \mathrm{M} 1-1$ & PPII-like, g+/g- & & $\mathrm{d}_{\mathrm{H} 3-01}(2.12)$ & \\
\hline $2 \mathrm{M} 1-3$ & $\alpha, \mathrm{g}+/ \mathrm{g}+$ & & $\mathrm{d}_{\mathrm{H} 3-01}(1.99)$ & \\
\hline $3 M 1-6$ & $\beta, \mathrm{t}+/ \mathrm{t}-$ & $\mathrm{d}_{\mathrm{H} 1-\mathrm{O} 1}(2.41), \mathrm{d}_{\mathrm{H} 2-\mathrm{O} 2}(2.18), \mathrm{d}_{\mathrm{H} 3-\mathrm{O} 3}(2.17)$ & & \\
\hline $3 \mathrm{M} 1-1$ & PPII-like, g+/g & & $\mathrm{d}_{\mathrm{H} 3-01}(2.11), \mathrm{d}_{\mathrm{H} 4-02}(2.11)$ & \\
\hline $3 \mathrm{M} 1-2$ & $\alpha, \mathrm{g}+/ \mathrm{g}+$ & & $\mathrm{d}_{\mathrm{H} 3-01}(2.98)$ & $d_{H 4-01}(2.15)^{a}$ \\
\hline $4 M 1-5$ & $\beta, \mathrm{t}+/ \mathrm{t}-$ & $d_{\mathrm{H} 1-01}(2.41), d_{H 2-02}(2.18), d_{H 3-03}(2.16), d_{H 4-04}(2.16)$ & & \\
\hline $4 \mathrm{M} 1-1$ & PPII-like, g+/g- & & $d_{H 3-01}(2.08), d_{H 4-02}(2.10), d_{H 5-03}(2.11)$ & \\
\hline $4 \mathrm{M} 1-2$ & $\alpha, g+/ g+$ & & $\mathrm{d}_{\mathrm{H} 3-01}(3.00), \mathrm{d}_{\mathrm{H} 4-02}(3.00)$ & $\mathrm{d}_{\mathrm{H} 4-01}(2.14)^{\mathrm{a}}, \mathrm{d}_{\mathrm{H} 5-02}(2.25)^{\mathrm{a}}$ \\
\hline $5 \mathrm{M} 1-3$ & $\beta, \mathrm{t}+/ \mathrm{t}-$ & $\begin{array}{c}d_{H 1-01}(2.54), d_{H 2-02}(2.40), d_{H 3-03}(2.54) \\
d_{H 4-04}(2.54), d_{H 5-05}(2.54)\end{array}$ & & \\
\hline $5 \mathrm{M} 1-2$ & PPII-like, g+/g- & & $\begin{array}{l}\mathrm{d}_{\mathrm{H} 3-01}(2.07), \mathrm{d}_{\mathrm{H} 4-02}(2.08) \\
\mathrm{d}_{\mathrm{H} 5-03}(2.10), \mathrm{d}_{\mathrm{H} 6-04}(2.11)\end{array}$ & \\
\hline $5 \mathrm{M} 1-1$ & $\alpha, g+/ g+$ & & $\mathrm{d}_{\mathrm{H} 3-01}(2.99), \mathrm{d}_{\mathrm{H} 4-02}(3.00)$ & $\begin{array}{c}\mathrm{d}_{\mathrm{H} 4-01}(2.13)^{\mathrm{a}}, \mathrm{d}_{\mathrm{H} 5-02}(2.23)^{\mathrm{a}} \\
\mathrm{d}_{\mathrm{H} 6-03}(2.24)^{\mathrm{a}}\end{array}$ \\
\hline
\end{tabular}

${ }^{a} n_{h}$ (Numbers of atoms in structure cyclized by hydrogen bond) $=12$.

RHF/STO-3G followed by RHF/6-31G, (C) RHF/STO-3G followed by B3LYP/6-31G, (D) RHF/STO-3G followed by B3LYP/6-31+G(d,p) and (E) RHF/6-31G. As shown in Table 7, the PPII models converged to PPII-like $(\mathrm{g}-/ \mathrm{g}+)$ or $\beta$-extended $(\mathrm{t}-/ \mathrm{t}+)$ structures, except for when method (A) was used, which resulted in the $g-/ \mathrm{t}+$ conformer. These results indicate that the PPII conformation of the alanine oligomer in gaseous phase disappeared during chain propagation when method (B) was used. It is important to note that the PPII type conformer is obtained only when method (A) (STO-3G instead of 6-31G) was used for the right-handed model.
Intramolecular hydrogen bonding. Peptides form intramolecular hydrogen bonds between the $\mathrm{NH}$ hydrogen and the carbonyl group in neighboring peptide groups. Examples of hydrogen bonding are shown in Figure 2. The hydrogen bonding can be classified into three patterns as follows: 'A', 'B' and ' $\mathrm{C}$ ', as shown in Tables 8 and 9. Pattern ' $A$ ' was observed in the $\beta$-extended conformation and has the numbers of atoms $\left(n_{\mathrm{h}}\right)$ in cyclized structure by hydrogen bond of 5 (hydrogen bond in the same monomer unit). Pattern ' $\mathrm{B}$ ' $\left(\mathrm{n}_{\mathrm{h}}=7\right.$ : hydrogen bond between the adjacent unit) and ' $\mathrm{C}$ ' $\left(n_{\mathrm{h}}=10-12\right.$ : hydrogen bond between units separated by 2 or 3 units) were observed in the PPII- 
like and $\alpha$-helix conformations, respectively. Because the length of the hydrogen bond $\left(\mathrm{d}_{\mathrm{H}-\mathrm{O}}\right)$ is less $3 \AA\left(\alpha\right.$-helix: $\left.\mathrm{d}_{\mathrm{H}-\mathrm{O}}=2.08 \AA^{18}\right)$, the bonds with $\mathrm{d}_{\mathrm{H}-\mathrm{O}}$ less than $3.00 \AA$ are shown in the tables, and each $\mathrm{d}_{\mathrm{H}-\mathrm{O}}$ value is classified into three ranges as follows: $1.99-2.26 \AA, 2.42-2.54 \AA$ and 2.98-3.00 $\AA$.

In the 'amide type' conformer, the numbers and patterns of hydrogen bonds were not affected by the rotational directions, and therefore, only the results for the left-handed conformers are shown in Table 8 . In the $\beta$-extended conformation, strong hydrogen bonds of type ' $\mathrm{A}$ ' with $\mathrm{d}_{\mathrm{H}-\mathrm{O}}=2.15-2.18 \AA$ were formed. In the PPII-like conformation, strong hydrogen bonds of type ' $\mathrm{B}$ ' with $\mathrm{d}_{\mathrm{H}-\mathrm{O}}=2.08$ $2.14 \AA$ were formed. However, in the $\alpha$-helix conformations, both ' $\mathrm{B}$ ' with $\mathrm{d}_{\mathrm{H}-\mathrm{O}}=2.98-3.00 \AA$ (week) and ' $\mathrm{C}$ ' with $\mathrm{d}_{\mathrm{H}-\mathrm{O}}=2.14-2.26 \AA$ (strong) hydrogen bonds were formed. In pattern ' $\mathrm{C}$ ', the hydrogen bonds are formed between the amino acid units separated by 2 or 3 units, and in the 2-mer and 3- to 5-mers, the numbers of atoms $\left(\mathrm{n}_{\mathrm{h}}\right)$ are 10 and 12 , respectively. Because the $\Delta \mathrm{E}$ values for the $\alpha$-helix conformation decrease as $\mathrm{x}$ increases (see Figure 1), it is estimated that the stability of the $\alpha$-helix conformation during chain propagation resulted in pattern ' $\mathrm{C}$ ' with strong integrated intramolecular hydrogen bonding.

In the 'methyl type', as shown in Table 9 (left-handed as an example), the numbers and patterns of the hydrogen bonds are different from those in the 'amide type'. First, in all of the $\beta$-extended conformations, 'A' type hydrogen bonds $\left(\mathrm{d}_{\mathrm{H} 1-\mathrm{O} 1}=2.16-2.54 \AA\right)$ between the $\mathrm{N}$-end $(\mathrm{NH})$ and the neighboring peptide group were formed. Second, in the 2-mer with the left- (2M1-3) and right-handed (2M2-13) $\alpha$-helix conformations, strong ' $\mathrm{B}$ ' type hydrogen bonds $\left(\mathrm{d}_{\mathrm{H} 3-\mathrm{O} 1}=1.99 \AA\right)$ and ' $\mathrm{A}$ ' type hydrogen bonds $\left(\mathrm{d}_{\mathrm{H} 2-\mathrm{O} 2}=2.17 \AA\right)$ were formed, respectively, and no ' $C$ ' type hydrogen bonds were observed. Third, the hydrogen bonding is affected by the rotational direction. In the 2-mer with the right-handed $\alpha$-helix (2M2-13) conformation, a weak ' $\mathrm{A}$ ' type hydrogen bond $\left(\mathrm{d}_{\mathrm{H} 1-\mathrm{O} 1}=2.59 \AA\right)$ between the $\mathrm{N}$-end and the peptide group was formed but in the left-handed (2M1-3) conformation, this hydrogen bond was not formed.

The unique energies and conformation of the 'methyl type' are related to these results compared with the 'amide type'. Because the 'methyl type' is more synthetically primitive than the 'amide type' end group, the results calculated for the 'methyl type' are very interesting. It has been reported ${ }^{15}$ that the conformation of a hydrated alanine oligomer is affected by the structures of the end groups. In general, the conformation of an $\alpha$-helical peptide is strongly affected by hydration. Therefore, we are planning to estimate the conformational end group effects in oligopeptides during hydration based on the results obtained in this study.

\section{CONCLUSION}

The conformational convergent calculations of alanine oligomers from 2- to 7-mer were performed using QCCs.

The numbers of conformers decreased with increases in the monomer unit numbers, and the dihedral angle distributions $(\varphi / \psi)$ of the 4 - to 7 -mers converged to three types (that is, $\alpha$-helix ( $g+/ g+$ or $\mathrm{g}-/ \mathrm{g}-)$, PPII-like $(\mathrm{g}+/ \mathrm{g}-$ or $\mathrm{g}-/ \mathrm{g}+)$ and $\beta$-extended $(\mathrm{t}+/ \mathrm{t}-$ or $\mathrm{t}-/ \mathrm{t}+)$ in the order of decreasing energy). The stabilities $(\Delta \mathrm{E})$ of the $\alpha$-helix conformations increased with increases in the monomer unit numbers. These calculated results supported ' $\alpha$-helix preferable' of polyalanine because of the strong intramolecular hydrogen bonds between amino acids located two units apart. The $\varphi / \psi$ types of $\alpha_{\mathrm{R}}$-helix $(\mathrm{g}-/ \mathrm{g}-)$ and $\beta$-extended $(\mathrm{t}-/ \mathrm{t}+)$ calculated were the same as previously reported values obtained by experiment and calculations for alanine oligomers. However, the PPII-like $(\mathrm{g}-/ \mathrm{g}+)$ conformation was different from the reported PPII $(\mathrm{g}-/ \mathrm{t}+)$ conformation and is considered to be a $2.2_{7}$ ribbon $(\mathrm{g}-/ \mathrm{g}+)$ because of the number of amino acid residues in one turn and the atoms in structure cyclized by hydrogen bonds were close to those of the 2.27 ribbon.

Differences between the numbers of convergent conformers, energies and structures of the 'amide type' and 'methyl type' were found. The number of converged 'methyl type' conformers was larger than the number of 'amide type' conformers. No energy differences $\left[\mathrm{E}_{(\mathrm{R})}-\mathrm{E}_{(\mathrm{L})}\right]$ between the left- and right-handed 'amide type' conformers were observed. However, the 'methyl type' conformers converged to $\beta$-extended and $\alpha$-helix conformations. The main chain of the 'methyl type' conformer largely kinked at the $\mathrm{N}$-end. These results are related to the properties of the 'methyl type' because of the structure of the $\mathrm{N}$-end and the intramolecular hydrogen bonding.

1 Parchansky, V., Kapitan, J., Kaminsky, J., Sebestick, J. \& Bour, P. Ramachandran plot for alanine dipeptide as determined from Raman optical activity. J. Phys. Chem. Lett. 4, 2763-2768 (2013)

2 Schweitzer-Stenner, R. Distribution of conformations sampled by the central amino acid residue in tripeptides inferred from amide I band profiles and NMR scalar coupling constants. J. Phys. Chem. B 113, 2922-2932 (2009).

3 Shi, Z., Oison, C. A., Rose, G. D., Baldwin, R. L. \& Kallenbach, N., R., Polyproline II structure in a sequence of seven alanine residues. Proc. Natl Acad. Sci. USA 99, 9190-9195 (2002)

4 Woutersen, S. \& Hamm, P. Structure determination of trialanine in water using polarization sensitive two-dimensional vibrational spectroscopy. J. Phys. Chem. B 104, $11316-11320$ (2000).

5 Woutersen, S., Pfister, R., Hamm, P., Mu, Y., Kosob, D. S. \& Stock, G. Peptide conformational heterogeneity revealed from nonlinear vibrational spectroscopy and molecular-dynamics simulations. J. Chem. Phys. 117, 6833-6840 (2002).

6 Graf, J., Nguyen, P. H., Stock, G. \& Schwalbe, H. Structure and dynamics of the homologous series of alanine peptides. J. Am. Chem. Soc. 129 1179-1189 (2007)

7 Mirkin, N. G. \& Krimm, S. Conformation dependence of the $\mathrm{C} \alpha \mathrm{D} \alpha$ stretch mode in peptides 1 isolated alanine peptide structures. J. Phys. Chem. A 111, 5300-5303 (2007).

8 Kentsis, A., Mezei, M., Gindin, T. \& Osman, R. Unfolded state of polyalanine is a segmented polyprorine II helix. PROTEINS: Structure, Function, and Bioinformatics 55, 493-501 (2004).

9 Kobayashi, M. \& Sato, H. Examinaion of conformations of isotactic methyl methacrylate oligomers by quantum chemical calculation. Kobunshi Ronbunnshu 64, 119-127 (2007)

10 Kobayashi, M. \& Sato, H. Conformational analysis of ethylene oxide and ethylene imine oligomers by quantum chemical calculation. Polymer Journal 40, 343-349 (2008).

11 Kobayashi, M., Takahashi, M. \& Sato, H. Conformational analysis for hydrated ethylene imine oligomer model by quantum chemical calculations. Polymer Journal 41 880-887 (2009).

12 Kobayashi, M. \& Sato, H. Structure analysis for hydrate model of ethyleneimine oligomer by quantum chemical calculation. Pharmacol. Pharm. 1, 60-68 (2010)

13 Gaussian 03 User's Reference, (Gaussian Inc., Carnegie, PA, USA, 2003).

14 Rigaudy, J. \& Klesney, S. P. Nomenclature of Organic Chemistry, Section E 483 (Pergamon Press, Oxford, 1979).

15 Makowska, J., Liwo, A., Zmudzinska, W., Lewandowska, A., Chmurzynski, L. \& Scheraga, $\mathrm{H}$. A. Like-charged residues at the ends of oligoalanine sequences might induce a chain reversal. Biopolymers 97, 240-249 (2011).

16 Pace, C. N. \& Scholtz, J. M. A helix propensity scale based on experimental studies of peptides and proteins. Biophys. J. 75, 422-427 (1998)

17 Berg, J. M., Tymoczko, J. L. \& Stryer, L. Biochemistry 5th edn (W. H. Freeman \& Co., New York, NY, USA, 2002).

18 Wikipedia 'Secondary structure' http://ja.wikipedia.org/wiki. Accessed 7 April 2013.

Supplementary Information accompanies the paper on Polymer Journal website (http://www.nature.com/pj) 